\title{
Digital Dashboards for Smart City Governance: A Case Project to Develop an Urban Safety Indicator Model
}

\author{
Alberto De Marco, Giulio Mangano, Giovanni Zenezini \\ Department of Management and Production Engineering, Politecnico di Torino, Corso Duca degli Abruzzi 24, \\ 10129 Turin, Italy \\ Email: alberto.demarco@polito.it, giulio.mangano@polito.it, giovanni.zenezini@polito.it
}

Received March 2015

\begin{abstract}
This paper illustrates a case project to design a digital dashboard for governing the urban safety of an Italian city and proposes a methodology for the definition of a set of safety measurement indicators. Results show that the method is easy to be used to identify the most crucial areas of the city, in several domains of application that have been identified. The study can substantially support policy makers in the development of their strategies and in the measurement of the effectiveness of their decisions.
\end{abstract}

\section{Keywords}

Public Safety, Urban Performance Indicators, Torino, Digital Dashboards

\section{Introduction}

In 2007, for the first time in the history of mankind, more people were living in cities than in rural areas. The urbanization trend is furthermore continuing, and predictions show that in 2050 , around $65 \%$ to $70 \%$ of the world population will live in the cities [1]. In response to these challenges a surge of interest in improving the livability of community and a growing commitment by public institutions to develop framework in order to plan livable cities has risen up [2]. Many authors have developed comprehensive panel of indicators able to monitor the effects of policy efforts [3], clarify their mission and translate it into actions [4]. As a matter of fact, current cities are also complex environments, where a massive numbers of connection networks between citizens, public entities and businesses thrive [5]. In this context, managing and leveraging ICT to make a better city life emerges as one possible tool to better manage the radical changes underway in current times, [6] [7]. Such concept can be expressed by the usage of ICT systems such as e-government dashboards [8], which elaborate and analyze data originated from the deployment of wireless sensors and technologies on the urban territory, which are now capable of collecting an impressive amount of information. Furthermore, recent developments in the field of data analytics and big data and the ever increasing availability of gps location-based records that have ended up in a variety of dashboards (such as intelligent operations centers) are an effective instrument for city 
planning, management and performance evaluation.

Thus, the identification of the crucial variables associated with a dashboard appears to be of paramount importance. The selection of proper data for the effectiveness of the measurement system based on the dashboard appears to be a key aspect too. On the one hand a huge amount of data is required in order to carry out robust analysis. On the other hand data collected need to be exhaustive and representative so that the real world is described.

In order to refine the development of dashboards associated with the measurement of performance in urban environment, this paper proposes a methodology that aims at defining a set of indicators for citizens' safety via a case study application through the use of digital dashboards. These indicators are elaborated dynamically by a digital dashboard, and then substantiated on a visual map. As a matter of fact, this study is based on a project related to the integration of two dashboards, which were developed to enhance the capability of real-time dynamic city governance.

The paper is structured as follows. In the first part, we investigate the methodologies mainly used for elaborating performance indicators in the urban context, providing some application examples. Then, the methodology for developing the safety and security indicators is shown together with their application on past series of data.

\section{Cities' Performance Measurement}

Through new sources of information nowadays cities are able to create insight, innovation, opportunity and real jobs that will increase prosperity and, more in general, the quality of life [9].

In this context, the computation of indicators is often aimed at the measurement of the Quality of Life (QoL) that is a concept extremely complex affected by many different factors [10]. It can be seen as a multidimensional notion as it consists of the basic needs for a good life, health, safe environment, good social relationships, freedom to choose what someone likes [11]. Actually, the use of indicators has a long tradition in the assessment of economic performance, environment, and quality of life [12]. Indicators appear to be very important because they allow to make proper decisions and at the same time to better and clearly communicate city performance not only to citizens, but also to tourists, visitors and potential investors. Indicators of quality of life can be split up into objective indicators (life expectancy, crime rate, GDP, poverty rate, school attendance) and subjective indicators (sense of community, sense of safety, happiness and relationship with family, etc [11]. Thus, indicators are not necessarily numbers, since in many cases they can be informal signs or labels [13]. One of the best-known indicators for assessing city performance is the City Development Index (CDI). The CDI is a readjustment of the Human Development Index (HDI) [1]. It is based on five sub-indexes: urban infrastructure (water, sewers, electricity and communication), waste treatment, health, education and gross domestic product. The urban performance indicators are often related to the measurement of the public safety associated with a specific area [14]. Public safety can be assessed not just through measurable phenomena such as crimes committed in urban areas, but also taking into account the perception of safety, which may depend on the time of day, the condition of the surrounding environment (e.g. a degraded environment, dark streets) or the presence of menacing people (e.g. drug dealers) [15]. From a methodological point of view, the estimation of the quality of life is based on the collection of a variety of indicators that are then combined in order to construct a composite indicator [16]. In recent years new technologies have enriched the methodologies to measure all these aspects and the integration of remote sensing and census data within a GIS framework is largely used in many studies [17].

Dashboards are often adopted since they are useful tools able to harness diverse and disperse data in order to support decision making processed also related to local governance [18]. They are indicator-based in the sense that they are structured by combining different indicators that represent different processes [19]. Dashboards allow being constantly aware about the global level of performance [20]. An increasing amount of aspects of human life can be more and more traced back through diverse digital footprints and, when aggregated, can reveal emerging patterns [21]. Generally speaking, dashboards are aimed at collecting, summarizing and presenting information from multiple sources [22].

These tools can substantially improve productivity and accelerate the innovation processes [23]. According to reference [24], there are three different sources of data that may be useful at the urban level, namely data coming from individuals carrying location-aware devices, from businesses moving their activities on line, and from governments that are releasing an increasing share of their data in open formats. These emerging sources of data 
are associated not only with mathematical, statistical and computer science, but with behavioral ones [25]. With huge amount of data interdisciplinary collaborations are advisable in order to avoid quality data problems. For instance, information systems experts are required to understand how data have been collected, stored, processed and retrieved [26].

\section{Research Methodology}

This research has been conducted through the following steps. First data about the adverse events have been collected, and each event has been grouped into one of seven different categories. For each category some types are associated. Then, a correlation analysis among the categories and the types has been performed in order to identify the most significant ones. In this way it has been possible to create an aggregated model with three different levels.

The outcome of the research is a classification of the indicators on three aggregation levels. The first level, or level 0, consists of raw data in the database. Data were provided by the Consorzio Sistemi Informativi (CSI) of Piemonte Region, that is the Regional Agency for Information and Technology Services and it is composed of events that occurred in the city of Torino from 01/01/2011 to 04/02/2012. CSI is responsible for warehousing and analyzing data coming from various sources, such as for instance the Firefighter Department, local Police and the Regional Environment Agency. These events represents wrongdoings from citizens or issues arising from faults of maintenance of the public good, and the all incidents. The events detected are updated daily on the database, and are structured in 24 types and in turn grouped in 7 Categories; the events are geo-located and structured as shown in Table 1.

\subsection{Correlation Analysis}

A statistical analysis is performed in order to examine the significant correlations. The correlation analysis has a twofold objective: i) the definition of clusters containing events related to different types and different categories; ii) the exclusion from the indicators pool of those Types or Categories that show no substantial correlation with other Types or Categories.

The main objective of the research was to elaborate indicators able to capture in an immediate way the impact of the events on the quality of life of the citizens. This is obtained by grouping those events that show a significant level of mutual correlation. The same analysis is carried out on both levels of aggregation (Categories and Types), following a hierarchical order. Therefore, if two Categories show a significant correlation, the correlation is also explored on the Types contained in those two Categories. Finally, a correlation analysis is performed within each Category.

The linear correlation is measured through the Pearson coefficient, by reason of its simplicity and straightforwardness [27]. Then, a scatterplot is used to assess in a qualitative and simple way the existence of other kind of non-linear correlation. Finally, p-values are considered in order to verify the reliability of the Pearson correlation coefficients. The correlation is significant when the p-value is less or equal to 0.05 [28]. Further analysis is performed on the correlation within each of the 7 categories.

Finally, the outcome of the statistical analysis is the elaboration of the three-level set of indicators. The correlation analysis was performed using the statistics package Minitab ${ }^{\circledR}$.

\subsection{Aggregation Model}

First, the analysis of the sample was carried out considering the absolute frequency of events belonging to the types occurring in fixed time steps, recorded on every district of Torino, the main city of Piedmont Region, Italy. The population density of each city district has been used as a normalization factor for the different event frequencies, so that they can be compared properly.

Table 1. Record of an event.

\begin{tabular}{ccccc}
\hline Date \& Time & Address & Category & Type & Lat Lon \\
\hline 2011-01-01 00:59:00 & BELFIORE & Distress & Fire & 1395937.91 \\
& (VIA) & 4989633.477 \\
\hline
\end{tabular}


The modus operandi of the aggregation process can be explained as follows. We identify the number of events that occurred in an interval of time in a certain district of Torino and related to the types that compose one indicator localized at level-1 of our model. After the normalization, these two amounts are added together, creating the aforementioned aggregated indicator. In a similar way other aggregated indicators are computed. Their sum gives the indicators of the second aggregate level. Finally, the sum of all these indicators gives, a global indicator of safety.

Once the values of the aggregated indictors were defined, it was necessary to identify the critical thresholds. The thresholds have been estimated, for each level of aggregation, through the calculation of the quartiles, which were evaluated on the basis of the entire sample. Through these thresholds it has been possible to determine a color attributable to each degree of criticality.

\section{Case Study}

A threshold of 0.1 was chosen for two categories to be suitable for a further analysis.

Not surprisingly, we found some significant correlations between the two categories "Parking infraction" and "Road Accidents", meaning that more infractions committed positively reflect on the increase of accidents on the road. By the same rationale, faults with the maintenance of public goods, represented in the Category "Renovation", will affect the flow of road traffic ("Road access").

Some negatively correlated categories are also found. For instance, we can suppose that when public officers have to intervene in case of public nuisance, it is because streets are occupied with social gatherings, e.g. night life, live concerts and so on, hence drivers are not able to park their cars, therefore committing less parking infraction (correlation coefficient: -0.345). Much less immediate is instead the negative correlation between "Disturbances" and "Road access".

The categories coupled for further analysis are the following:

- Distress-Renovation

- Distress-Road access

- Renovation-Road access

- Renovation-Road accidents

- Renovation-Parking infraction

- Road access-Road accidents

- Road access-Parking infraction

- Road accidents-Parking infraction

For the second step of the statistical analysis, correlations between types pertaining to the aforementioned categories are investigated.

As far as the correlation 'between' categories, some significant correlations between the two categories Road accidents-Parking infraction have emerged. For instance, the type of event denominated "Material Damages" shows a 0.492 correlation coefficient with parking infraction caused by car parking in front of private driveways ("Driveway), and a 0.457 with infraction on parking spot reserved to disabled drivers ("Disabled").

Further consideration may be proposed on certain types related to the category "Road access". For instance, we might advance the hypothesis that a relation exists between distress issues with the public good or with private condominiums, and a temporary worsening of road access. In fact, a positive correlation is found between the event type "Obstacle on the road" pertaining to the "Road access" category, and two event types pertaining to the "Distress" category, namely "Rubble drop" (coefficient $=0.369$, p-value $=0$ ) and "Other distress" (coefficient $=0.365$, p-value $=0$ ). Furthermore, we may add that a proper access to road is, among other things, enabled by fewer parking infractions. The analysis, however, invigorates this assumption only if we consider two types related to one event, that is a construction site, which reflects on two categories. In fact, "Unmarked work in progress" is an issue when it comes to road access, and it is positively correlated (coefficient $=0.367$, pvalue $=0$ ) with "Work in progress" which refers to a parking infraction. Similar conclusions cannot be drawn for the type "Traffic halt" that shows significant correlation with none of the types pertaining to the category "Parking infraction". Concerning the correlation "within", results show that a significant degree of correlation is found within two categories, namely "Parking infraction" and "Disturbances".

Finally, no significant non-linear correlation is found between categories. 


\section{Indicators Formulation and Mental Model}

In the proposed model, the indicators can be visualized in a hierarchical order, where at level 0 there are the Types of events detected. The model is enabled by the dashboard capability of data aggregation and visualization on different domains, namely indicator under study, time and geographical area. The scope of our work is to provide with an indicator related to the quality of life of citizens in terms of personal safety and security, therefore the upper level of aggregation, or third level, is denominated "Global Safety". The safety of the individual is seen as a matter of personal safety and road safety. Hence, two indicators compose the second level of aggregation: "Road safety" and "Personal Safety". Each of these indicators is a composition of sub-indexes that are a consequence of the statistical analysis performed on data. The indicators are shown in Figure 1.

Keeping constant the temporal and spatial dimension, at an arbitrary value of 15 days and district extension, respectively, the analysis is carried out by moving on the descriptive dimension.

As already mentioned, the quartiles have been taken into account in order to set up the thresholds for each indicator. The definition of the quartiles with the related thresholds is associated with 4 different colors so that to provide with an immediate idea about the level of criticality of each specific indicators, as presented in Table 2 and Table 3, which show these values for the global safety index.

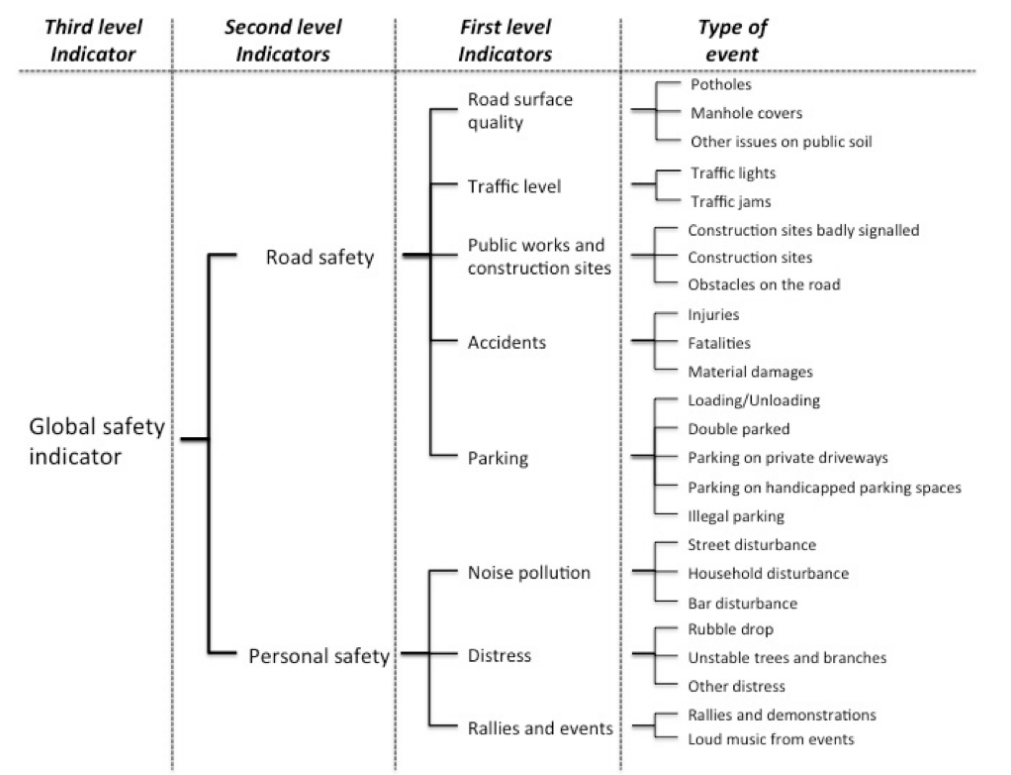

Figure 1. Hierarchical mental model.

Table 2. Quartiles values for the global safety index.

\begin{tabular}{rc} 
I quartile & 0.0106079 \\
Median & 0.0137682 \\
III quartile & 0.0305189 \\
\hline
\end{tabular}

Table 3. Criticality color legend for global safety index.

\begin{tabular}{ccc}
\hline value interval & Criticality & descriptive color \\
\hline$<0.0106079$ & very low \\
Between 0.0106079 and 0.0137682 & Low \\
between 0.0137682 and 0.0305189 & High \\
$>0.0305189$ & very high \\
\hline
\end{tabular}


The behavior of the indicators is illustrated on a two-axis table. The vertical one is the time step considered (2 weeks) and the horizontal one represents five districts of Torino (chosen for the sake of conciseness out of 11). Each cell shows the sum of the normalized frequencies related to that specific indicator, and the color of the cell reveals the level of criticality for those indicators in each district of the city.

\section{Discussion of Results}

The analysis reveals a marked critical situation for four urban districts: I, VI, VII, VIII. The reason why this phenomenon occurs is mainly due to the connotations that distinguish these areas.

The 1st and 8th district represent the most central urban areas where the highest number of shops, pedestrian streets and local markets is concentrated. Moreover, it is precisely in these areas that the night life is particularly florid with a number of pubs and restaurants, which often involve a significant increase in noise pollution. We can then logically perceive a correlation between these connotations and high criticality Individual Quietness and Security Index. Finally another reason can be attributed to this phenomenon. Although massive redevelopment projects have been implemented in these areas in recent years, until last decades the areas close to the old town and Porta Nuova train station were neglected and subject to the phenomena of crime. Even today, sporadically in some narrow constituencies, events of crime and aggression may occur with a greater incidence than in other areas of the city, especially in the evening.

Furthermore, we are able to motivate the criticality of Road Safety Index in these two districts, highlighting the commercial and social vivacity of the areas, which attracts a significant flow of vehicles, thereby creating increased risks of accidents or traffic jams. I and VIII coincide with the historical center of the city. Here viability and urban planning (i.e. poor roads, width of carriageways often inadequate) do not facilitate the circumstance, leading to a worsening of the situation.

Regarding districts VI and VII the reasons of criticality for Road Safety Index and Individual Quietness and Security Index, and consequently of the global index, are to be found in other reasons. Contrary to the districts I and VIII, these other two areas are dormitory suburbs that extend to the edge of town. They are characterized by calm nights, poor business during the day and the presence of some industrial areas extended to the northern boundaries. The main causes of concern for this area lie in the morphology and in its marked trait as a gateway to the motorways linking Torino to Milano and the Alpine tunnels. Also part of the VII district covers the hillside, from where is it possible to reach the surrounding towns. This trait involves a massive transit of cars and trucks, which put a strain on the infrastructure. In addition, the confluence of the rivers increases the risk of floods and landslides in the hilly areas.

As a result, it seems then that the model of aggregation is consistent. A final important consideration is related to the evolution of the level of criticality along the time axis. During the months of August and July the criticality indexes decreased significantly in all constituencies. This is due to the emptying of the city at the summer period. This highlights the strong relation that the city of Turin has toward the secondary sector of the economy. The partial summer closure of industrial plants and related industries, strongly influences the behavior of citizens.

\section{Implications}

This work originates some important theoretical implications. Usually the safety is evaluated with very simple indicators, such as crime rates or thefts per inhabitant. On the contrary, the proposed methodology allows considering a unique indicator for the level of individual safety obtained from the synthesis of a set of heterogeneous indicators. These indicators are not necessarily directly related to the safety, but their behavior has proved to be significant for it. For example, a hole in a street or a rubble drop from buildings does not influence the perception of danger that a citizen might feel, even if they can heavily impact on its level of safety and in turn on the quality of life. Consequently the field associated the urban safety is enlarged. This appears crucial especially in modern cities. In fact their increasing level of complexity calls for more and more aspects that are required be taken into account into the analysis. However, a higher level of integration between the different actors operating in urban systems that collect data is advisable in order to enable an even more complete analysis.

This work calls for further research about a unique and horizontal visualization of urban indicators, such as provided by ICT Dashboards. Dashboards' usefulness has been historically proven based on their successful implementation in performance measurement systems and performance management in private companies. How- 
ever, it has yet to be tested equally essential for public entities, especially in the light of these new methodologies for developing indicators.

The practical implications arising from the use of the model for the development of indicators in the field of urban security, concerns both citizens and policy makers. For the both of them the practical implications can have ex-ante and ex-post interpretations.

In fact, citizens can use the indicators generated from the model ex-ante not just to identify the areas that can be risky for their personal safety (e.g. areas to avoid during night or urban district to avoid because of hazards due to bad weather) but also to identify those areas that might be a source of stress, such as crowded or busy areas. On the other hand, citizens can use the indicator ex-post to make housing or business choices, thus affecting not only the housing market, but also the socio-economic ecosystem of the city. For example, an individual may choose to buy a new apartment in an area that offers a better quality of life or run a business in attractive areas.

At the same time, policy makers will be able to exploit the results arising from the model to identify high-risk areas, and implement in a cost-effective manner all interventions of maintenance on the city's infrastructures. As already mentioned, policy makers can use the indicators ex-post to design preventive operations aiming at ensuring the safety of citizens or at increasing their quality of life. For example, policy makers could optimize shifts of police forces by relocating them to risky areas, or define new plans for roads maintenance to reduce the risk of accidents, or even promote the economic development of certain areas by dedicating equipped services and pedestrian areas.

\section{Conclusion}

In this paper a methodology for the evaluation of the level of citizen safety is proposed. Safety is one of the crucial pillars of the quality of life issue and its evaluation has been typically difficult to be carried out. In this study the level of safety is computed as a normalized aggregation of different indicators associated with the occurrence of events recorded by an ICT agency in the Municipality of Torino. Each event belongs to a specific type that in turn is related to a category. This structure has allowed work with a hierarchical approach, aggre- gating level by level the indicators taken into account. Though the identification of quartiles, 4 different thresholds have been identified for each indicator in each district of Torino. In this way the most crucial areas of the city for each domain could have actually emerged. The proposed tool has proved to be relatively easy to be used, so that policy makers can adopt it in the formulation of its guidelines related to safety and in the setting of its budgets. Moreover the methodology reaffirms the importance of collaboration and integration among different public agencies, that thanks to the sharing of information can enhance the control of the territory, test their strategies and improve the effectiveness of the decisions. The information issue will be more crucial in the cities of the future, wherein the ICT will impact and influence all the aspects of the daily citizens' life. However, the methodology needs to be refined in the sense that in this first step each event has considered in the analysis with the same importance. Research is currently addressing in the development of a model able to assign a weight to the events according to their impact to the safety of citizens. Furthermore the methodology will be tested in other cities in order to see how different policy makers facing different issues will handle with the proposed indicator.

\section{Acknowledgements}

The authors are grateful to IBM Italia for financing and supporting this project.

The authors also wish to thank Mr. Lorenzo Lavagno, former graduate student at Politecnico di Torino, for his precious collaboration.

\section{References}

[1] UNDP (2010) Frequently Asked Questions: The 2010 Human Development Index (HDI), New Horizons, UNDP, International Human Development Indicators. http://hdrstats.undp.org/en/tables/

[2] Miller, H.J., Witlox, F. and Tribby, C.P. (2013) Developing Context-Sensitive Livability Indicators for Transportation Planning: A Measurement Framework. Journal of Transport Geography, 26, 51-64. http://dx.doi.org/10.1016/j.jtrangeo.2012.08.007

[3] Botterman, S., Hooghe, M. and Reeskens, T. (2012) One Size Fits All? An Empirical Study into the Multidimensionality of Social Cohesion Indicators in Belgian Local Communities. Urban Studies, 49, 185-202. 
http://dx.doi.org/10.1177/0042098010397397

[4] Carli, R., Dotoli, M., Pellegrino, R. and Ranieri, L. (2013) Measuring and Managing the Smartness of Cities: A Framework for Classifying Performance Indicators. IEEE International Conference on Systems, Man, and Cybernetics (SMC), Manchester, 13-16 October 2013, 1288-1293.

[5] Neirotti, P., De Marco, A., Cagliano, A.C., Mangano, G. and Scorrano, F. (2014) Current Trends in Smart City Initiatives: Some Stylised Facts. Cities, 38, 25-36. http://dx.doi.org/10.1016/j.cities.2013.12.010

[6] Pan, J.G., Lin, Y.F., Chuang, S.Y. and Kao, Y.C. (2011) From Governance to Service-Smart City Evaluations in Taiwan. IEEE International Joint Conference on Service Sciences (IJCSS), Taipei, 25-27 May 2011, 334-337. http://dx.doi.org/10.1109/IJCSS.2011.74

[7] Lombardi, P., Giordano, S., Farouh, H. and Yousef, W. (2012) Modelling the Smart City Performance. InnovationThe European Journal of Social Science Research, 25, 133-145.

[8] Jans, G. and Verdegem, P. (2006) DashGov: Developing an e-Government Dashboard. In IADIS international Conference e-Society Location, Dublin.

[9] Harrison, C. and Donnelly, I.A. (2011) A Theory of Smart Cities. Proceedings of the 55th Annual Meeting of the ISSS, 17-22 July 2011, Hull, UK. Vol. 55, No. 1.

[10] Hajduova, Z., Andrejovky, P. and Beslerova, S. (2014) Development of Quality of Life Economic Indicators with Regard to the Environment. Procedia-Social and Behavioral Sciences, 110, 747-754. http://dx.doi.org/10.1016/j.sbspro.2013.12.919

[11] Petrosillo, I., Costanza, R., Aretano, R., Zaccarelli, N. and Zurlini, G. (2013) The Use of Subjective Indicators to Assess How Natural and Social Capital Support Residents' Quality of Life in a Small Volcanic Island. Ecological Indicators, 24, 609-620. http://dx.doi.org/10.1016/j.ecolind.2012.08.021

[12] Hezri, A. and Dovers, S.R. (2006) Sustainability Indicators, Policy and Governance Issues for Ecological Economics. Ecological Economics, 60, 86-99. http://dx.doi.org/10.1016/j.ecolecon.2005.11.019

[13] Ronchi, E., Federico, A. and Musumeci, F. (2002) A System Oriented Integrated Indicator for Sustainable Development in Italy. Ecological Indicators, 2, 197-210. http://dx.doi.org/10.1016/S1470-160X(02)00045-6

[14] Hebenton, B., Jou, S. and Chang, Y.C. (2010) Developing Public Safety and Crime Indicators in Taiwan. Asian Criminology, 5, 45-67. http://dx.doi.org/10.1007/s11417-009-9081-8

[15] Christin, D., Roßkopf, C. and Hollick, M. (2013) uSafe: A Privacy-Aware and Participative Mobile Application for Citizen Safety in Urban Environments. Pervasive and Mobile Computing, 9, 695-707. http://dx.doi.org/10.1016/j.pmcj.2012.08.005

[16] Pissourios, I.A. (2013) An Interdisciplinary Study on Indicators: A Comparative Review of Quality of Life, Macroeconomic, Environmental, Welfare and Sustainability Indicators. Ecological Indicators, 34, 420-427. http://dx.doi.org/10.1016/j.ecolind.2013.06.008

[17] Li, G. and Weng, Q. (2007) Measuring the Quality of Life in City of Indianapolis by Integration of Remote Sensing and Census Data. International Journal of Remote Sensing, 28, 249-267. http://dx.doi.org/10.1080/01431160600735624

[18] Wickramasuriya, R., Ma, J., Berryman, M. and Perez, P. (2013) Using Geospatial Business Intelligence to Support Regional Infrastructure Governance. Knowledge-Based Systems, 53, 80-89. http://dx.doi.org/10.1016/j.knosys.2013.08.024

[19] Mori, K. and Christodoulou, A. (2012) Review of Sustainability Indices and Indicators: Towards an New City Sustainability Index (CSI). Environmental Impact Assessment Review, 32, 94-106. http://dx.doi.org/10.1016/j.eiar.2011.06.001

[20] Voskamp, I.M. and Van de Ven, F.H.M. (2015) Planning Support System for Climate Adaptation: Composing Effective Sets of Blue-Green Measures to Reduce Urban Vulnerability to Extreme Weather Events. Building and Environment, 83, 159-167. http://dx.doi.org/10.1016/j.buildenv.2014.07.018

[21] Batty, M. (2012) Smart Cities, Big Data. Environment and Planning B: Planning and Design, 39, 191-193. http://dx.doi.org/10.1068/b3902ed

[22] Miller, A. and Cioffi, J. (2004) Measuring Marketing Effectiveness and Value: The Unisys Marketing Dashboard. Journal of Advertising Research, 44, 237-243. http://dx.doi.org/10.1017/S0021849904040334

[23] Iandoli, L., Quinto, Q., De Liddo, A. and Shum, S.B. (2012) A Debate Dashboard to Enhance Online Knowledge Sharing. VINE: The Journal of Information and Knowledge Management Systems, 42, 67-93.

[24] Arribas-Bel, D. (2014) Accidental, Open and Everywhere: Emerging Data Sources for the Understating of the Cities. Applied Geography, 49, 45-63. http://dx.doi.org/10.1016/j.apgeog.2013.09.012 
[25] Barton, D. and Court, D. (2012) Making Advanced Analytics Work for You. Harvard Business Review, 90, 79-83.

[26] Hazen, B.T., Boone, C.A., Ezell, J.D. and Jones-Farmer, L.A. (2014) Data Quality for Data Science, Predictive Analytics, and Big Data in Supply Chain Management: An Introduction to the Problem and Suggestions for Research and Applications. International Journal of Production Economics, 154, 72-80.

[27] Lee Rodgers, J. and Nicewander, W.A. (1988) Thirteen Ways to Look at the Correlation Coefficient. The American Statistician, 42, 59-66. http://dx.doi.org/10.1080/00031305.1988.10475524

[28] Rice, W.R. (1988) A New Probability Model for Determining Exact P-Values for $2 \times 2$ Contingency Tables When Comparing Binomial Proportions. Biometrics, 44, 1-22. http://dx.doi.org/10.2307/2531892 